\title{
Pelatihan Google Apps For Education Untuk Guru MTSN di Kabupaten Karawang
}

\author{
Budi Arif Dermawan*1, Betha Nurina Sari², Tesa Nur Padilah ${ }^{3}$ \\ ${ }^{1,2,3}$ Universitas Singaperbangsa Karawang; Jl. H.S. Ronggowaluyo Telukjambe Timur - \\ Karawang 41361, Telp. (0267) 641177 \\ ${ }^{3}$ Program Studi Informatika, FASILKOM UNSIKA, Karawang \\ e-mail: *1 budi.arif@staff.unsika.ac.id, ${ }^{2}$ betha.nurina@ staff.unsika.ac.id, \\ ${ }^{3}$ tesa.nurpadilah@staff.unsika.ac.id
}

\begin{abstract}
Abstrak
Dua MTsN yang jadi mitra pengabdian masayarakat ini belum terdaftar sebagai pengguna Google Application for Education (GAfE), sehingga belum maksimal menggunakan fasilitas Google Applications untuk kepentingan kegiatan sekolah, baik untuk administrasi sekolah, proses belajar mengajar di kelas, tugas sekolah, maupun kegiatan administrasi guru dan siswa. Pemanfaatan Google Applications walaupun bersifat gratis dan memiliki fasilitas yang sama dengan perangkat lunak berlisensi, bagi para guru merupakan hal baru yang masih asing dan sulit dimanfaatkan. Solusi yang ditawarkan berupa pelatihan Google Applications for Education di dua MTsN Karawang bagi para guru sehingga fasilitas gratis ini dapat dimanfaatkan secara maksimal.
\end{abstract}

Kata kunci-google apps for education, kegiatan belajar mengajar

\begin{abstract}
Two MTsN who are community service partners have not yet been registered as users of Google Application for Education (GAfE), so they have not maximally used Google Applications facilities for the benefit of school activities, both for school administration, teaching and learning in classes, school assignments, and teacher administration activities and students. Using Google Applications even though it is free and has facilities that are exactly the same as licensed software, for teachers is a new thing that is still unfamiliar and difficult to use. The solution offered is in the form of mentoring the use of Google Applications for Education in two Karawang MTsN for teachers so that these free facilities can be fully utilized.
\end{abstract}

Keywords — google apps for education, teaching and learning activities

\section{PENDAHULUAN}

Google Applications (Google Apps) atau yang sekarang diberi nama baru G-Suite adalah layanan produktivitas bisnis berbasis Cloud Computing yang memungkinkan pekerjaan dilakukan tanpa terbatas waktu dan media. Layanan Google Apps memungkinkan pelaku bisnis melakukan aktivitas di mana saja dengan media pendukung teknologi terkini. Fasilitas yang lengkap pada Google Apps memungkinkan bisnis dapat sepenuhnya didukung oleh Google Apps. Layanan standar Google Apps antara lain: email dengan domain personal, penyimpanan data dengan kapasitas yang besar, aplikasi pengolah kata (word processor), aplikasi pengolah data tabular (spreadsheet), aplikasi presentasi (presentation), aplikasi pengisian formulir yang disimpan dalam spreadsheet (form). Fasilitas Google Apps dapat menggantikan aplikasi kantor berlisensi yang harus dibeli secara terpisah. Integrasi layanan Google Apps lainnya berupa 
Google Calender, Google Talk, Google Sites, telah memberikan keuntungan besar bagi kolaborasi dan produktivitas pengguna Google Apps[1].

Dukungan Google terhadap pendidikan diwujudkan melalui Google Application for Education (GAfE) yang diberikan secara gratis untuk pendidikan di dunia, termasuk di Indonesia. Menurut analisis biaya Forrester [2], biaya berlangganan layanan Google kurang dari biaya yang dibutuhkan untuk berlangganan layanan surat elektronik Microsoft Exchange. Biaya tersebut ditujukan untuk layanan Google Application for Bussiness sebesar 50 USD per pengguna per tahun.

Komputer dan aplikasi di dalamnya bagi para guru bukan merupakan hal baru, namun saat ini baru terbatas pemanfaatan pada aplikasi pengolah kata, presentasi dan pengolah data secara sederhana. Aplikasi kantor rata-rata sudah terpasang pada komputer masing-masing walaupun merupakan perangkat lunak "bajakan" yang rentan terhadap klaim ilegal dari pihak berwenang. Pemanfaatan Google Applications walaupun bersifat gratis dan memiliki fasilitas yang sama persis dengan perangkat lunak berlisensi, bagi para guru merupakan hal baru yang agak asing dan sulit dimanfaatkan. Fasilitas yang memungkinkan para guru melakukan banyak hal secara mudah dan sistematis apalagi dengan dukungan integrasi secara online tidak menjadi daya tarik dikarenakan kurangya pemahaman tentang bagaimana memanfaatkannya.

MTsN di Karawang banyak yang belum terdaftar sebagai pengguna Google Application for Education, hal ini yang menyebabkan belum bisa menggunakan fasilitas Google Applications untuk kepentingan kegiatan sekolah, baik untuk administrasi sekolah, proses belajar mengajar di kelas, tugas sekolah, maupun kegiatan administrasi guru dan siswa. Hal inilah yang mendasari untuk pengusulan kegiatan pengabdian masayarakat dengan topik Pelatihan Google Apps for Education (GAfE) untuk Guru MTsN di Kabupaten Karawang.

\section{METODE PENELITIAN}

Kegiatan Pelatihan Google Apps for Education (GAfE) untuk Guru MTsN di Kabupaten Karawang merupakan Program Pengabdian Kepada Masyarakat yang diselengggarakan oleh LPPM Universitas Singaperbangsa Karawang. Mitra dalam Program ABDIMAS ini yaitu MTsN 2 Karawang, dan MTsN 4 Karawang. Metode pelaksanaan kegiatan pelatihan ini dimulai dari tahap sosialisasi, pelatihan di laboratorium komputer masing-masing sekolah, pendampingan, dan evaluasi terhadap materi yang telah disampaikan. Materi yang disampaikan mulai dari Pengelolaan surel, pengenalan dan penggunaan Google Drive, pemanfaatan Google Docs untuk membuat artikel dan surat otomatis, penggunaan Google Sheets untuk membuat daftar tujuan surat, dan pemanfaatan Google Forms untuk pengumpulan data dan pembuatan evalasi belajar secara online. Dalam kegiatan pelatihan ini diikuti oleh 30 peserta dari masing-masing sekolah. Pelatihan dan pendampingan ini diharapkan dapat mengoptimalkan penggunaan layanan Google Apps di dua MTsN Kabupaten Karawang.

\section{HASIL DAN PEMBAHASAN}

\subsection{Hasil Kegiatan}

Pelatihan Google Apps for Education memiliki banyak keuntungan yang dapat dimanfaatkan oleh MTsN 2 dan MTsn 4 karawang. Beberapa manfaat yang dihasilkan dari pelatihan terdiri dari:

a. Kepemilikan Akun Google

Google Apps for Education merupakan sebuah layanan yang disediakan Google yang dapat digunakan secara gratis. Syarat yang ditentukan hanya berupa kepemilikan akun Google dalam menggunakan layanan yang disediakan. Sejumlah guru teridentifikasi telah memiliki akun Google hanya sebatas digunakan untuk keperluan registrasi sosial media, namun belum dimanfaatkan secara optimal. Pelatihan ini diselenggarakan bukan hanya bertujuan agar para guru memiliki akun, namun tujuan lain adalah agar pemilik akun dapat memanfaatkan akun yang telah dimiliki dengan optimal. 
b. Media Penyimpanan yang Fleksibel

Proses kegiatan belajar mengajar pada kedua MTsN dapat dikatakan belum memanfaatkan teknologi secara maksimal. Salah satu-nya adalah bentuk pemberkasan dan dokumentasi yang minim. Pelatihan ini dimanfaatkan agar para guru dapat memahami proses penyimpanan yang lebih aman dan fleksibel menggunakan layanan yang disediakan Google.

c. Media Penulisan yang Inovatif

Satu dari beberapa layanan yang terdapat pada Google Drive adalah Google Docs. Google Docs dalam pelatihan ini dimanfaatkan untuk guru maupun siswa agar dapat membuat dokumen secara interaktif dan memungkinkan adanya kolaborasi dalam pengerjaan tugas kelompok. Inovasi media dihadirkan oleh Google Docs dengan terdapat beberapa fitur interaktif seperi pemberian komentar, live chat, dan riwayat pengerjaan.

d. Pengumpulan Data

Google Drive dalam pelatihan ini telah dimanfaatkan untuk media penyimpanan data dan media penulisan. Selain itu Google Drive juga dapat dimanfaatkan untuk pengumpulan data. Data yang dimaksud dapat berupa biodata, daftar hadir kegiatan, dan berkas lainnya. Pengumpulan data ini dapat dilakukan dengan menggunakan Google Drive sebagai media penyimpanan (storage), sedangkan Google Forms untuk proses memasukkan data, dan Google Sheets sebagai list data.

e. Media Evaluasi Pembelajaran Interaktif

Evaluasi pembelajaran dalam bentuk kertas (paper) sudah banyak membuat siswa bosan. Google Drive memberikan solusi berupa penggunaan Google Forms untuk keperluan evaluasi hasil belajar. Jenis media tersebut dapat dikatakan interaktif dengan memiliki beberapa fitur berupa pengaturan limit waktu, penyisipan gambar, pembatasan waktu pengerjaan, dan informasi keseluruhan dari evaluasi tersebut.

\subsection{Pembahasan}

Kegiatan Pengabdian Kepada Masyarakat yang dilakukan terbagi menjadi beberapa tahapan, yaitu:

a. Sosialisasi

Sosialisasi dilakukan dengan mengumumkan secara langsung kepada Kepala Sekolah dan Perwakilan Guru MTsN 2 dan 4 Karawang sebagai mitra. Total peserta yang diharapkan hadir adalah 30 orang dari setiap sekolah. Sosialisasi juga dilakukan dengan menggunakan undangan yang ditujukan kepada peserta dari pihak mitra. Sosialisasi dilakukan selama Bulan September 2018 atau 1 bulan sebelum pelaksanaan Workshop Google Apps for Education. Sosialisasi dilakukan dengan tujuan agar calon peserta dapat memahami manfaat dan sasaran dari kegiatan ini.

b. Pelaksanaan Workshop

Pelaksanaan Workshop dilakukan dua tahap, yaitu dilaksanakan di masing-masing sekolah sesuai kesepakatan pada tahap sosialisasi. Pelaksanaan Workshop GAfE dijadwalkan sebagai berikut:

1) MTsN 2 Karawang

Pelaksanakan dilakukan pada Sabtu, 6 Oktober 2018 mulai pukul 09.00 s.d 16.00 WIB.

2) MTsN 4 Karawang

Pelaksanakan dilakukan pada Sabtu, 19 Oktober 2018 mulai pukul 09.00 s.d 16.00 WIB.

c. Pendampingan

Pendampingan dilakukan baik melaui komunikasi grup Whatsapps antara tim Abdimas dengan peserta maupun melalui Whatsapp pribadi peserta. Terkait kesulitan belajar materi dan serangkaian kegiatan dikomunikasikan melalui media komunikasi tersebut. Selain itu bisa melalui komunikasi via email atau langsung tatap muka. Komunikasi dilakukan secara intensif dengan beberapa peserta saat masa pendampingan. Konsultasi saat pendampingan dilakukan oleh salah satu peserta dari MTsN 2 Karawang yang membahas mengenai pembuatan evaluasi belajar secara daring yang ditunjukkan pada Gambar 1. 


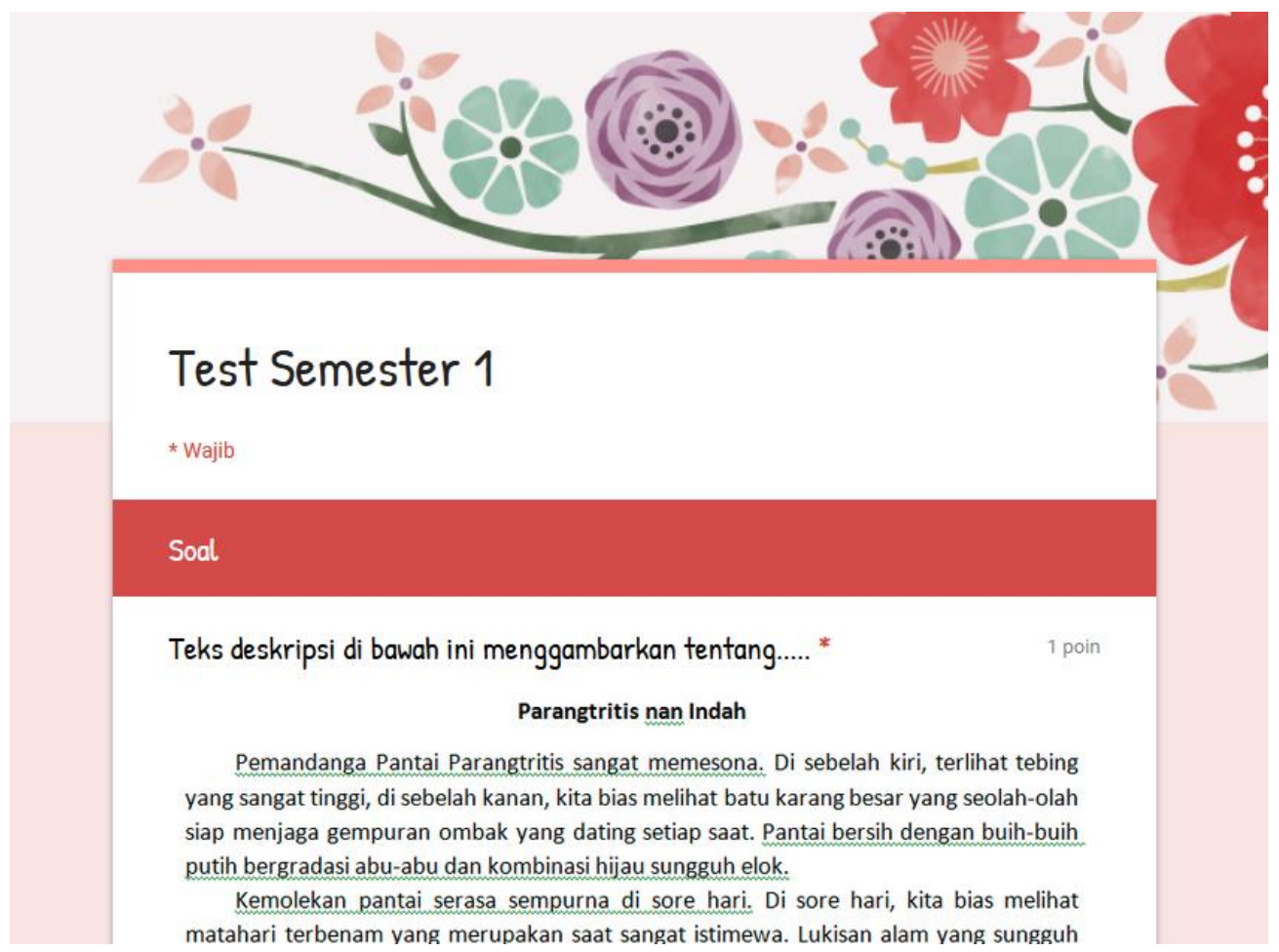

\section{Gambar 1 Media Evaluasi Belajar}

Saran diberikan kepada peserta berupa pembuatan soal dipecah menjadi beberapa sesi untuk menghindari kejenuhan siswa dalam membaca dan mengerjakan soal tersebut. Setelah soal selesai, kemudian dilakukan uji coba dalam latihan pekan evaluasi yang ditunjukkan pada Gambar 2.

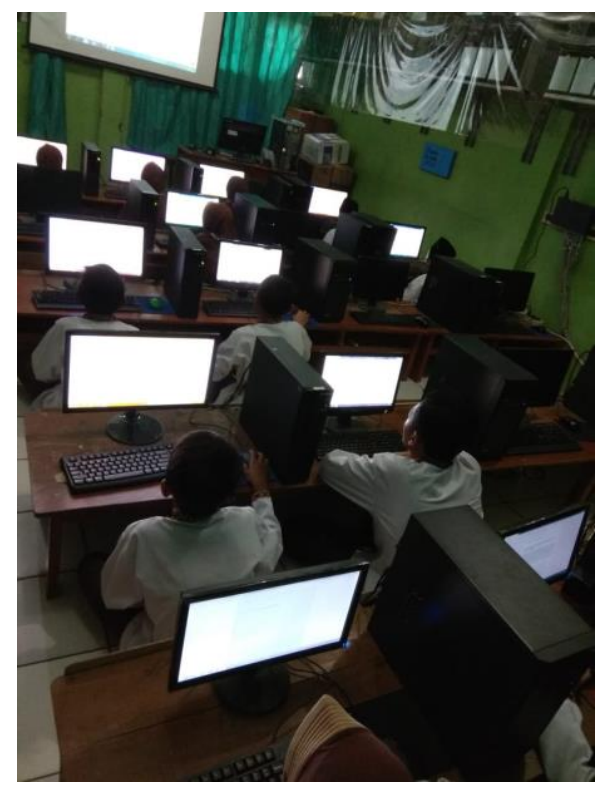

Gambar 2 Pelaksanaan Uji Coba Media Evaluasi Belajar

Hasil dari uji coba tersebut mendapatkan kesan positif baik dari siswa maupun guru bersangkutan. Menurut salah satu siswa yang mengerjakan, pengerjaan evaluasi dengan menggunakan layanan Google ini lebih interaktif dari pada evaluasi berbasis konvensional. 
Senada dengan siswa tersebut, guru berpendapat bahwa media evaluasi belajar menggunakan layanan Google lebih memudahkan tugas guru baik dalam pelaksanaan evaluasi maupun dalam penilaian. Kemudahan yang dihasilkan berupa proses dari pembuatan soal, pelaksanaan pengerjaan, dan proses penilaian menjadi jauh lebih singkat.

d. Evaluasi

Evaluasi dilaksanakan pada hari Minggu tanggal 3 November 2018, setelah kegiatan workshop di kedua MTsN tersebut terlaksana. Evaluasi bertujuan untuk melihat kemajuan terkini peserta, perbaikan proses kegiatan dan rencana keberlanjutan. Beberapa pertanyaan yang berhubungan dengan pemanfaatan layanan disampaikan oleh peserta Workshop. Pertanyaan yang disampaikan diantaranya berupa:

1) Bagaimana cara membatasi waktu pengerjaan.

2) Bagaimana cara menampilkan nilai dari evaluasi belajar.

3) Adakah fitur yang dapat membatasi waktu pengerjaan untuk setiap soal atau setiap sesi.

Dua dari tiga pertanyaan yang disampaikan dapat didiskusikan dan dipelajari oleh peserta Workshop selama sesi evaluasi, sedangkan pertanyaan ketiga disampaikan melalui media komunikasi dikarenakan keterbatasan waktu pada sesi evaluasi.

\section{KESIMPULAN}

Pelatihan Google Apps for Education selama 1 hari di masing-masing sekolah memberikan dampak positif dari manfaat yang diperoleh, serta dapat ditarik kesimpulan sebagai berikut:

a. Pelatihan yang dilaksanakan memberikan edukasi berkaitan dengan layanan Google yang belum maksimal dimanfaatkan dan menambah wawasan para guru dalam memanfaatkan layanan Google Apps for Education.

b. Pelatihan yang diberikan dapat dimanfaatkan dengan baik berupa keaktifan dalam penggunaan Google Mail, pengerjaan dokumen berkolaborasi, pembuatan media evaluasi belajar secara daring, dan pendokumentasian hasil dari evaluasi belajar.

c. Proses pelatihan tidak hanya dilakukan dalam satu tahun, namun diperlukan keberlanjutan pendampingan dan evaluasi dengan tujuan mengembangkan kemampuan dalam pemanfaatan layanan Google Apps for Education di dua MTsN Kabupaten Karawang.

\section{SARAN}

Hasil evaluasi selama pelatihan dan pendampingan memberikan beberapa saran berupa:

a. Pembinaan keberlanjutan untuk peserta agar meningkatkan kemampuan dalam menggunakan layanan Google Apps for Education.

b. Membina MTsN 2 dan MTsN 4 Karawang dalam menggagas kerja sama untuk meningkatkan layanan dari Standard Edition ke Education Edition.

c. Membuat skema pelatihan selanjutnya untuk mencapai pemanfaatan layanan yang terintegrasi.

\section{UCAPAN TERIMA KASIH}

Tim Pengabdian mengucapkan terima kasih terhadap banyak pihak yang turut membantu dalam terselenggaranya program ini diantaranya: 
a. Universitas Singaperbangsa Karawang melalui Program Pengabdian Bagi Masyarakat di Lempaga Penelitian dan Pengabdian Masyarakat (LPPM) yang telah memberikan dana untuk pelaksanaan program ini.

b. Kepala sekolah beserta para guru dan staf administrasi pada MTsN 2 dan MTsN 4 Karawang yang telah kooperatif dalam menyelenggarakan program ini.

c. Pengabdi, Panitia, dan Narasumber yang telah mencurahkan waktu dan tenaga sehingga program ini terselenggara dengan baik.

\section{DAFTAR PUSTAKA}

[1] D. R. Herrick, "Google This ! Using Google Apps for Collaboration and Productivity," pp. 55-63, 2009.

[2] T. Schadler, "Should Your Email Live In The Cloud? A Comparative Cost Analysis Should Your Email Live In The Cloud ?," 2009. 